\title{
Elimination of routine testing in patients under- going cataract surgery allows substantial savings in laboratory costs. A brief report
}

\author{
[L'élimination des tests de routine, avant l'opération de la cataracte, permet de \\ réduire de façon importante les dépenses de laboratoire. Un rapport sommaire.]
}

Ngozi Imasogie FRCA, David T. Wong MD, Ken Luk BSc, Frances Chung FRCPC

Purpose: To evaluate the possible cost savings when routine preoperative testing is discontinued in ambulatory cataract surgery patients.

Methods: A policy was introduced at our hospital to stop routine testing in ambulatory cataract patients. Consecutive patients' medical records were analyzed in a four-month period pre- and a fourmonth period post-discontinuation of routine laboratory tests. Ambulatory cataract surgery is performed under topical (and sometimes retrobulbar block) anesthesia with iv sedation. Co-morbidities, perioperative events, frequency and cost of tests ordered were compared for the two groups. Average costs per patient preand post-discontinuation of routine tests, and total possible cost savings were calculated.

Results: One thousand two hundred and thirty-one patients were studied; 636 had routine laboratory tests and 595 had no routine laboratory tests. The ratios of gender, co-morbidities and perioperative events were similar in the two groups. There was a significant reduction in the number of tests ordered after the new policy was introduced, from 5.8 tests per patient to 0.4 tests per patient. The cost of tests per patient was reduced from Can $\$ 39.67$ to $\$ 4.01$.

Conclusion: In ambulatory cataract surgery, over $90 \%$ savings in laboratory costs is possible after elimination of routine tests.

Objectif : Évaluer l'économie possible si on supprime l'examen de routine préopératoire chez les patients qui subissent une opération ambulatoire de la cataracte.

Méthode : Il a été décidé à notre hôpital de ne plus procéder aux tests de laboratoire de routine chez les patients ambulatoires opérés pour une cataracte. Les dossiers médicaux des patients qui se sont successivement présentés pendant les quatre mois qui ont précédé l'arrêt de ces examens, et pendant les quatre mois qui ont suivi cet arrêt, ont été analysés. L'opération ambulatoire de la cataracte se fait sous anesthésie topique, et parfois sous bloc rétrobulbaire, avec une sédation iv. La comorbidité, les incidents périopératoires, la fréquence et le coût des tests demandés dans les deux groupes ont été comparés. Le coût moyen par patient avant et après l'arrêt des tests de routine et l'économie totale possible ont été calculés.

Résultats : L'étude a porté sur 1231 patients dont 636 ont eu des tests de laboratoire et 595 n'ont pas eu d'examen de routine. Les deux groupes avaient des caractéristiques similaires quant au sexe des patients, à la comorbidité et aux incidents périopératoires notés. II y a eu une réduction significative du nombre de tests demandés, passant de 5,8 à 0,4 par patient après l'introduction de la nouvelle politique. Le coût des tests est passé de 39,67 \$CAN à 4,0I \$ par patient.

Conclusion : En chirurgie ambulatoire de la cataracte, on peut économiser au-delà de $90 \%$ du coût de laboratoire en éliminant les examens de laboratoire de routine.

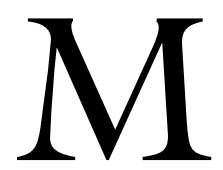

ORE than 1.5 million cataract operations are being performed in the U.S. alone per year, ${ }^{1}$ costing approximately

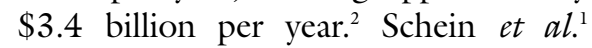
showed that elimination of routine laboratory testing prior to cataract surgery did not adversely affect patient outcome. Based on Schein's findings, the department of anesthesiology at our hospital introduced a new policy of discontinuing routine testing. This study is designed to determine the comparative cost savings of eliminating routine preoperative tests before cataract surgery.

From the Department of Anesthesia, Toronto Western Hospital, University Health Network, University of Toronto, Toronto, Ontario, Canada.

Address correspondence to: Dr. David T. Wong, Department of Anesthesia, EC 2-046, Toronto Western Hospital, 399 Bathurst Street,

Toronto, Ontario M5T 2S8, Canada. Phone: 416-603-5118; Fax: 416-603-6494; E-mail: david.wong@uhn.on.ca

Accepted for publication June 10, 2002.

Revision accepted November 29, 2002. 


\section{Methods}

Institutional Research Ethics Board approval for the study was obtained. Consecutive cataract patients' charts were reviewed, during the period of June to September 2000 representing the patients who had routine preoperative tests (testing group), and June to September 2001, the patients who had no routine preoperative tests (non-testing group). A standardized technique of anesthesia was used; topical/block anesthesia with tetracaine, and $i v$ sedation with small doses of midazolam, fentanyl and/or propofol. Data collected included demographics, clinical data such as ASA class, past medical history, medications. Perioperative events (cancellations, intraoperative hypertension, arrhythmia, hypotension, and postoperative events such as unanticipated admission and readmissions) were collected.

The costs of the individual tests were ascertained from the hospital finance department. Based on the tests ordered and the cost of each test, total costs of laboratory tests of individual patients were calculated. To compare variables between the testing and nontesting groups, Student's t test was used for continuous data, and Chi-square test used for categorical data. $P<0.05$ was considered statistically significant.

\section{Results}

The total number of cataract patients studied was 1,$231 ; 636$ consecutive patients in a four-month period in the year 2000 (testing group) and 595 consecutive patients to a similar period in the year 2001 (non-testing group). The ratios of male to female sex and ASA status were similar in both groups. There was no difference in the incidence or the severity of co-morbidities in the two groups. The outcomes evaluated were perioperative hypertension, hypotension, bradycardia arrhythmias, myocardial ischemia, myocardial infarction, congestive heart failure, syncope, hypoglycemia, oxygen saturation of less than $90 \%$, and airway obstruction. There was no difference in the incidence of preoperative, intraoperative or postoperative events between the two groups (Table I). Two cases were cancelled in the testing group, and none in the non-testing group. One of the cancellations was due to inadequate time, while the other was rescheduled because of an emergency case. There was one readmission in the testing group; the patient was admitted five days postoperatively because of endophthalmitis.

There was, however, a significant reduction in the number of tests per patient ordered in the non-testing group, 0.4 tests per patient compared to 5.8 in the testing group (Table II). Specifically, there were reductions in ordering of complete blood count
TABLE I Perioperative events

\begin{tabular}{lllll}
\hline \multirow{2}{*}{ Preoperative events } & \multicolumn{2}{c}{ Testing group } & \multicolumn{2}{c}{ Non-testing } \\
& No & $\%$ & No & $\%$ \\
\hline Surgery cancelled & 2 & 0.3 & 0 & 0 \\
Surgery delayed & 0 & 0 & 0 & 0 \\
Intraoperative events & & & & \\
Hypertension treated & 1 & 0.2 & 4 & 0.6 \\
Bradycardia treated & 0 & 0 & 0 & 0 \\
Hypotension & 0 & 0 & & 0 \\
Hypoxia $\left(\mathrm{SpO}_{2} \leq 90 \%\right)$ & 0 & 0 & 0 & 0 \\
Airway obstruction & 0 & 0 & 0 & 0 \\
Syncope & 0 & 0 & 0 & 0 \\
Hypoglyceamia & 0 & 0 & 0 & 0 \\
Arrhythmia treated & 4 & 0.6 & 0 & 0 \\
Postoperative events & & & & \\
Unanticipated admission & 0 & 0 & 0 & 0 \\
Readmission to hospital & 1 & 0.2 & 0 & 0 \\
\hline
\end{tabular}

TABLE II Preoperative tests ordered for the testing and nontesting groups

\begin{tabular}{|c|c|c|c|c|c|}
\hline & \multicolumn{2}{|c|}{ Testing } & \multicolumn{2}{|c|}{ Non-testing } & Cost per test \\
\hline \multirow[t]{2}{*}{ Total numbers pts } & 636 & & 595 & & \\
\hline & No. & $(\%)$ & No. & $(\%)$ & $(\$)$ \\
\hline $\mathrm{CBC}$ & 595 & $93.5^{*}$ & 37 & $5.9^{*}$ & 3.45 \\
\hline INR/PTT & 30 & $4.7^{\star}$ & 2 & $0.3^{*}$ & 13.50 \\
\hline Sickle screen & 47 & $7.4^{*}$ & 7 & $1.1^{*}$ & 12.00 \\
\hline $\mathrm{Hb}$ electrophoresis & 6 & 0.9 & 0 & 0 & 34.00 \\
\hline Electrolytes & 443 & $69.6 *$ & 27 & $4.3^{*}$ & 2.30 each \\
\hline Creatinine/urea & 385 & $60.5^{*}$ & 27 & $4.3^{*}$ & 2.30 \\
\hline Glucose & 240 & $37.7 *$ & 14 & $2.2 *$ & 2.30 \\
\hline Other test (blood film) & 13 & 2.0 & 2 & 0.3 & 3.50 \\
\hline LFT & 5 & 0.8 & 0 & 0 & 15.00 \\
\hline ECG & 602 & 94.7 * & 46 & $7.2^{*}$ & 26.00 \\
\hline $\mathrm{ECHO}$ & 20.3 & 2 & 0.20 & 220 & \\
\hline Cardiac stress test & 1 & 0.16 & 1 & 0.16 & 58 \\
\hline CXR & 7 & 1.1 & 1 & 0.3 & 26.00 \\
\hline Number of test per pt. & $5.8^{*}$ & & $0.4^{*}$ & & \\
\hline Pts with no tests & 17 & $2.7^{*}$ & 532 & $89.4^{*}$ & $\mathrm{~N} / \mathrm{a}$ \\
\hline Range of cost $(\$)$ & $0-31$ & 8.95 & $0-30$ & & \\
\hline Average cost $(\$)$ & 39.67 & \pm 19.04 & 4.01 & $=18.92 *$ & \\
\hline Anesthesia consult & $47 \%$ & & $33 \%$ & & \\
\hline
\end{tabular}

LFT $=$ liver function test ECG $=$ electrocardiogram; ECHO = echocardiogram; $\mathrm{CXR}=$ chest $x$-ray; Pts, $\mathrm{pt}=$ patient $(\mathrm{s}) ; \mathrm{CBC}=$ complete blood count; INR = international normalized ratio; PTT = partial thromboplastin time; $\mathrm{ea}=\mathrm{each} ; \mathrm{N} / \mathrm{a}=$ not applicable; $\mathrm{Hb}=$ hemoglobin. ${ }^{*} P<0.05$ between testing non-testing groups.

(CBC), international normalized ratio/partial thromboplastin time, sickle cell screen, electrolytes, creatinine, urea, glucose, electrocardiogram in the non-testing group compared to the testing group. The cost per patient was $\$ 4.01 \pm 18.92$ in the nontesting group compared to $\$ 39.67 \pm 19.04$, in the testing group. A $90 \%$ reduction in laboratory costs per 
patient was achieved. A potential cost savings of $\$ 21,217.7$ was possible for the management of 595 patients $[(39.67-4.01) \times 595]$; 595 being a hypothetical number of patients in a four-month period. There was also a reduction in the proportion of patients referred to the anesthesia consult clinic to $33 \%$ compared to $47 \%$ before the guidelines were introduced but this was not statistically significant.

\section{Discussion}

Routine tests are of little value in low risk ambulatory surgery. ${ }^{1}$ Age alone should not be an indication for preoperative tests. ${ }^{3}$ Other studies have found that when abnormalities are found in routine laboratory tests, surgery has rarely been delayed nor the anesthetic management changed. ${ }^{4-7}$ Kaplan et al. found that only $0.22 \%$ of routine tests done prior to elective surgery showed abnormalities that could have influenced perioperative management. ${ }^{8}$ In our study there was no difference in perioperative morbidity between the two study groups (Table II).

The main finding of our study was that $90 \%$ of the cost of testing can be potentially saved by stopping routine tests. There was a significant reduction in the number of tests ordered in the non-testing group, 0.4 tests per patient compared to 5.8 in the testing group. For example, despite a $10 \%$ prevalence of anemia in the elderly population, routine $\mathrm{CBC}$ is not warranted. ${ }^{3}$ We reduced our CBC rate from $94 \%$ to $6 \%$. The incidence of perioperative events in the Schein study was $3.1 \%$ whereas the incidence in our study was $0.79 \%$.

Our study had no exclusion criteria and yet the findings were similar to that of Schein et al. ${ }^{1}$ There was no difference in morbidity or mortality between the two groups.

The study has several limitations. Firstly, laboratory cost savings are calculated potential savings. Most of the cost incurred by the laboratory is for salary of personnel. With elimination of routine laboratory testing, cost savings are minimal and this potential in savings cannot be realized until the number of personnel required for testing can be reduced. Secondly, our data was collected retrospectively and this may have led to an underestimation of the frequency of adverse events. Thirdly, the relatively small number of patients studied is too small to conclude definitely on the risks of adverse events associated with the elimination of laboratory testing (risk of a type II error).

Lastly, extrapolating from our study results, a subset of low risk ambulatory surgical patients requiring only local anesthesia and sedation may not require routine preoperative tests. ${ }^{9}$ However further study is required to establish the safety of this approach.
In summary, with ambulatory cataract surgery, over $90 \%$ savings in laboratory costs was possible after elimination of routine tests. Outcomes remained unchanged in this relatively small series of patients.

\section{Acknowledgements}

We acknowledge the cooperation and help of anesthesiologists and ophthalmologists at the Toronto Western Hospital, in making this study possible. We also thank Dajun Song and Tania DiRenna for their assistance in data collection and analyses.

\section{References}

1 Schein OD, Katz J, Bass EB, et al. The value of routine preoperative medical testing before cataract surgery. $\mathrm{N}$ Engl J Med 2000; 342: 168-75.

2 Steinberg EP, Javitt JC, Sharkey PD, et al. The content and cost of cataract surgery. Arch Ophthalmol 1993; 111: 1041-9.

3 Dzankic S, Pastor D, Gonzalez C, Leung JM. The prevalence and predictive value of abnormal preoperative laboratory tests in elderly surgical patients. Anesth Analg 2001; 93: 301-8.

4 Narr BJ, Warner ME, Schroeder DR, Warner MA. Outcomes of patients with no laboratory assessment before anesthesia and a surgical procedure. Mayo Clin Proc 1997; 72: 505-9.

5 Golub R, Cantu R, Sorrento JJ, Stein HD. Efficacy of preadmission testing in ambulatory surgical patients. Am J Surg 1992; 163: 565-70.

6 Gimbel HV, Hamilton RC. The value of medical testing before cataract surgery. Ophthalmic Practice 2000; 18: 166-70.

7 McKibbin M. The pre-operative assessment and investigation of ophthalmic patients. Eye 1996; 10: 138-40.

8 Kaplan EB, Sheiner LB, Boeckman AJ, et al. The usefulness of preoperative laboratory screening. JAMA 1985; 253: 3576-81.

9 Anonymous. Practice advisory for preanesthesia evaluation: a report by the American Society of Anesthesiologists Task Force on Preanesthesia Evaluation. Anesthesiology 2002; 96: 485-96. 